\title{
International Atomic Weights *
}

TWO changes in the table of atomic weights are recommended by the Committee on Atomic Weights of the International Union of Chemistry in its second report, which has just been published; the atomic weight of krypton is considered to be 83.7 instead of 82.9 , and of xenon 131.3 instead of 130.2. The Committee, which consists of Prof. G. P. Baxter (Cambridge, Mass.), Mme. P. Curie (Paris), Prof. P. Lebeau (Paris), and Prof. R. J. Meyer (Berlin), reports on all the atomic weight investigations published during the period Feb.-Oct. 1931 which have come to its attention; future reports will cover a period of twelve months. Authors of papers bearing on the subject are requested to send copies to each of the five members of the Committee at the earliest possible moment.

Elements of which the atomic weight has been determined during the period under review by physicochemical methods are: nitrogen, carbon, sulphur, fluorine, krypton, and xenon; chemical methods have been applied to the study of nitrogen, silver, chlorine, and iodine; physical (mass-spectrograph) measurements have been applied to the calculation of values for lithium, cæsium, boron, germanium, selenium, tellurium, tungsten, bromine, rhenium, ruthenium, and osmium, whilst a new determination of the relative proportions of the oxygen isotopes has been made by microphotometric evaluation of the band spectrum of oxygen.

Reference should first be made to the investigation last mentioned, because the results provide a new conversion factor for the calculation of 'chemical' atomic weights from 'physical' atomic weights, and emphasise the disparity between the two scales for the determination of atomic weights used respectively by chemists and by physicists. This " undesirable situation " arises from the fact that the chemical unit, $\mathrm{O}=16$, takes no account of the existence of the three isotopes of oxygen, $\mathrm{O}^{16}, \mathrm{O}^{18}$, and $\mathrm{O}^{17}$, present, according to Mecke and Childs, in the ratio $630 \pm 20: 1: 0 \cdot 2$. The physical unit is referred to the isotope $\mathrm{O}^{16}$, and hence the two scales differ by one or two parts in ten thousand. The propriety of employing hydrogen, helium, or $\mathrm{O}^{16}$ as a chemical standard has therefore been canvassed, but in Dr. F. W. Aston's opinion, communicated to the British Association last year, the present chemical standard amply satisfies all requirements of international atomic weights so far

* Union Internationale de Chimie. Table internationale des poids a tomiques. Deuxième rapport de la Commission des poids atomiques, 1932. (Paris: U.I. de C., 49 Rue des Mathurins.) as accuracy is concerned. The Committee agrees unanimously with Dr. Aston, and therefore does not propose a departure from the existing unit. The new conversion factor is 1.00022 , whilst the Naudé factor, at present in use, is 1.000125 .

Nitrous oxide has been found by Batuecas to have a normal density of $1.98042 \pm 0 \cdot 00005$ (not 1.98038 as given in the original), this value being the mean of twenty determinations. Cooper and Maass report values of 44.0054 and 64.059 for the molecular weight of carbon dioxide and sulphur dioxide respectively, leading to atomic weights of 12.0054 for carbon and 32.059 for sulphur. Patterson, Whytlaw-Gray, and Cawood, repeating the work of Moles and Batuecas, find the molecular weight of methyl fluoride to be $34 \cdot 046$, and are of opinion that the true atomic weight of fluorine lies nearer to $19 \cdot 010$ than to $19 \cdot 000$ (see NAture, 128, 375), despite Aston's view that fluorine is a simple element. By comparison of the densities of krypton and oxygen, Watson calculates the atomic weight of krypton to be $83 \cdot 71$, whilst WhytlawGray, Patterson, and Cawood, by comparison of the pressures at which xenon and oxygen possess the same density, find the atomic weight of xenon to be $131 \cdot 26 \pm 0 \cdot 005$.

Gravimetric determination of the ratio $\mathrm{Ag}: \mathrm{NH}_{3}$ by Baxter and Greene, combined with the ratio $\mathrm{Ag}: \mathrm{NO}_{3}$, gives, when chloride or dilute bromide solutions are used, the value 14.0078 for the atomic weight of nitrogen. Hönigschmid corrects the results of silver chloride analyses by Hönigschmid and Bedr Chan, and obtains a mean atomic weight for chlorine of $35 \cdot 456_{3}$ (gravimetric) or $35 \cdot 456_{7}$ (nephelometric). Thermal decomposition of iodine pentoxide, employed by Baxter and Butler, leads to the low value $I=126.905$, and the method is considered to be insufficiently precise. Combination of the ratios $2 \mathrm{Ag}: \mathrm{I}_{2} \mathrm{O}_{5}$ and $\mathrm{I}_{2}: \mathrm{I}_{2} \mathrm{O}_{5}$ affords the value 126.929 . Determinations of the ratio $\mathrm{AgI}: \mathrm{AgCl}$ by Hönigschmid and Striebel give the low value 126.917 $(\mathrm{Cl}=35 \cdot 457)$. Aston's value, $126.932\left(\mathrm{O}^{16}=16\right)$, corresponds with a chemical atomic weight of $126 \cdot 918$ or $126 \cdot 905$, according to the conversion factor employed, but is a mean of observed limiting values 126.907 and $126 \cdot 957$.

Calculation of atomic weights from mass spectra, using Naudé's equation, leads to the following results $(\mathrm{O}=16)$ : lithium 6.923 , cæsium 132.91 , boron $10 \cdot 806$, germanium $72 \cdot 65$, selenium 78.96 , tellurium 128.03 , tungsten 183.96 , bromine $79 \cdot 916$, rhenium $186 \cdot 22$, ruthenium, 101·1, osmium $190 \cdot 31$.

\section{Co-operation in Fisheries Investigations*}

THE twenty-fourth annual meeting of the International Council for the Exploration of the Sea was held in Copenhagen in March 1931. During the short interval of nine months between this meeting and the last, the general lines of work and instructions laid down by the Council have been followed. Three special conferences took place during the year, the first and second at Lowestoft, on the transplantation of plaice and on herring investigations, the third at Lisbon, on the sardine fisheries.

In reviewing the general work already accom. plished, it is shown that striking progress has been

* Report of British Delegates of the Meeting of the International Council for the Exploration of the Sea, held at Copenhagen, March 2328, 1931. Drawn up by Henry G. Maurice and D'Arcy W. Thompson.
Pp. 9. (London : Ministry of Agriculture, 1931.) made in the 'technique' of prognostication of the fisheries. In the administrative report of the Committee of the Northern North Sea, the chairman is able to state with regard to the haddock that the work has reached the stage where the yield of the North Sea haddock fisheries for eighteen months or two years ahead can be anticipated with great accuracy. The report of the Southern North Sea Committee records, not for the first time, a successful forecast of the East Anglian herring fishery; and the report of the North and Western Area Committee records the complete justification of a forecast made in the previous year of the trend of the Icelandic cod fishery.

Extensive cod-marking experiments are being carried out by Denmark in Greenland and Iceland and show an interchange between cod populations 
of Davis Straits and Iceland, the cod populations of Iceland being thought previously to be self-contained.

This year is the second International Polar Year, when polar hydrographical conditions will be specially investigated by all nations. It is hoped that intensive observations will be made of internal waves in the Southern Cattegat during a period of seven days in August. The English hydrographic programme includes an extension of the total current measurements which have been carried out at the Varne Lightship in the past.

The question as to whether the Limnological and the Plankton Committees should remain as separate entities was discussed, and it was decided to reconsider this at the next meeting.

Special scientific meetings on plankton and hydrology dealt with the conditions of plant life in the sea. Prof. Gran, as chairman of the Plankton Committee, reviewed recent work on the effects of phosphates and nitrates on the growth of plankton. From his ewn work he inclines to the belief that manganese and iron derived from coastal waters are necessary, in addition to phosphates and nitrates, for planktonic growth in Atlantic waters.
Dr. Henry Bigelow, of Woods Hole Oceanographical Institution, attended the meeting as a visitor and outlined plans for future work in the North Atlantic in which the North American Council on Fisheries Investigations might co-operate with the International Council. The Council expressed appreciation of the work to be carried out on the western side of the Atlantic, and declared that the moment is opportune to enter into close co-operation with both the Woods Hole Institution and the North American Council of Fisheries Investigations, and that this can best be achieved by close personal touch between the workers. The Council invite representatives of both bodies to take part regularly in its deliberations, in order to arrive at unity of plan and methods in the study of those fundamental problems which are similar or identical on both sides of the Atlantic.

The conclusions of the delegates are that the organisation is on a thoroughly sound footing; that its reputation in the scientific world has grown and continues to grow; that the welfare of the fishing industry demands the continuance of scientific investigations, and that the Council should be encouraged to continue its useful work.

\section{Forestry in Trinidad and Tobago*}

TWHE keynote of the Annual Report of the Forest Department of Trinidad and Tobago (Trinidad, May 1931) is to be found in the opening paragraph on "Forest Resources". The conservator, Mr. R. C. Marshall, is able to write: "As a result of a considerable amount of detailed field work during the last few years, we are now in a position, in regard to a considerable area of forest, to be able to substitute a clear picture of the stand of timber for the vague general idea with which, in the past, we have had to be content". Unfortunately, in far too large a proportion of the Empire forest departments this vague general idea of the forest resources still persists. The survey of the forests in Trinidad is being effected by the well-known method of running lines in carefully considered directions 100 chains apart and enumerating the trees on the lines, thus obtaining a one per cent enumeration; 6000 chains of lines were run in 1929 and 5600 in 1930.

From the enumeration surveys already made, it is now established that the Colony's 600,000 acres of forest contain a very large amount of wood. This is supported by the stock-taking effected on 1000 acres of mora (Dimorphandra mora) in Mayaro, and on 1000 acres of mixed forest in the Central Range Reserve, in which crappo (Carapa guianensis) and guatecare (Lecythis lavifolia) form the most plentiful of the useful species. Appendix D gives the data of the species found on these two areas and is of great interest. It has established the fact that the mora forest in its constitution is far more comparable with the pure forests of temperate regions, which provide the bulk of the timber of commerce. It is considered possible, therefore, that this type of forest gives possibilities of regulated commercial working or 'lumbering' in the Colony. These two types of forest are representative of a large proportion of the forests of the Colony. "Increased utilisation of our forest resources", writes the Conservator, "hinges mostly on getting together stocks of timber and seasoning them properly." In view of the fact that the Colony imported $£ 233,000$ of forest produce during the year,

* Trinidad and Tobago: Forest Department. Administration Report of the Conservator for the Year 1930. Pp. 22. (Trinidad : Government Printing Office, Port of Spain, 1931.) 18. this rightly forms one of the problems which is receiving the closest consideration.

The two most popular woods in the Colony are said to be cedar (Cedrus mexicana) and balata (Mimusops balata var. Cruegeri). The enumeration surveys have shown the very small proportion which these species bear to the total crop, and that the younger age classes are very deficient. It is with satisfaction that we read that working plans are being prepared, and that in the case of cedar they prescribe and control the yield. Other plans are in course of preparation, one for the control of the mangrove swamps close to Port of Spain, which are a very important source of fuel wood for the city.

The Report is replete with details of progress which will have a far-reaching effect on the prosperity of the Colony. Mention can only be made of interesting sylvicultural experiments and sowing and planting work; of investigations in connexion with forest soils in collaboration with Prof. Hardy, of the Soil Department of the Imperial College of Tropical Agriculture; and finally, in collaboration with the Trinidad Government Railway, a beginning has been made with wood preservation experiments in connexion with the treatment of mora sleepers. The administrators of the Colony are to be congratulated on the marked progress which their Forest Department has achieved in the past few years.

In Leaflet No. 4 of the Forest Department, Mr. R. C. Marshall deals with the "Forest Trees of Trinidad and Tobago, with Special Reference to their Timbers". The leaflet gives a reasonably complete list of the more prominent forest trees, stating the size to which various species grow, their relative abundance, and giving in a concise form some information as to the timber they produce. It is not, nor does it purpose to be, a complete list of all forest tree species. As noted above, there are 600,000 acres of forest in the Colony. With the exception of the mora forests, which are of special interest through the gregarious habit of mora and the large stocking per acre, practically all the remainder is of a very mixed type such as is common in tropical rain forest, to which category most of the forests belong. Two tabular statements are attached which show the trees by one foot girth 